\title{
A transição da educação infantil para o ensino fundamental narrada pelas crianças
}

\author{
The transition from early childhood education to
}

primary education narrated by children

\section{La transición de la educación de la primera infancia a \\ la escuela primaria narrada por los niños}

ECLEIDE CUNICO FuRLANETTO (iDa

Aline de Souza Medeiros (iDb

Karina Alves Biasoli (D)

\section{Resumo}

O presente estudo se propôs ampliar a compreensão sobre a passagem de crianças da Educação Infantil para o Ensino Fundamental. Para isso, foram ouvidas narrativas de crianças por acreditar que elas são capazes de contar o que lhes acontece e construir sentidos para suas experiências. O objetivo da pesquisa foi: analisar os sentidos atribuídos narrativamente por crianças a respeito da transição da Educação Infantil para o Ensino Fundamental. Sob o aporte teórico da pesquisa (auto)biográfica em Educação e da Sociologia da Infância, o estudo foi desenvolvido com seis crianças do primeiro ano do Ensino Fundamental oriundas de Escolas de Educação Infantil. Os resultados indicaram que a transição entre as duas escolas provocou algumas tensões, pois ao mesmo tempo em que as crianças se viam atraídas pelas inovações oferecidas pela nova escola, sentiam temores, lutos e sofrimentos, sobretudo, no que se refere à diminuição de oportunidades para brincar, ao acolhimento e à preparação da escola para recebê-los. Para algumas crianças, as perdas foram compensadas pelas novas aprendizagens, enquanto outras estavam sofrendo e não contavam com recursos suficientes, necessitando de maior apoio para se incluírem nessa nova etapa. Os adultos

\footnotetext{
a Universidade Cidade de São Paulo (UNICID), São Paulo, SP, Brasil. Doutora em Psicologia da Educação, e-mail: ecleide@terra.com.br

b Secretaria Municipal de Educação de São Bernardo do Campo, São Bernardo do Campo, SP, Brasil. Mestra em Educação, e-mail: alkins-msn@hotmail.com

c Universidade Cidade de São Paulo (UNICID), São Paulo, SP, Brasil. Doutora em Psicologia da Educação, e-mail: karinabiasoli@yahoo.com.br
} 
responsáveis pelo ensino, acolhimento e introdução da criança nessas instituições têm um papel preponderante na adaptação da criança nesta nova etapa. São eles que podem estar com as crianças, detectando suas necessidades, de forma a auxiliá-las a se inserirem neste novo contexto.

Palavras-chave: Pesquisa (auto)biográfica. Narrativas. Ensino fundamental de nove anos. Transição.

\begin{abstract}
This study aimed to broaden the understanding of children's transition from early childhood education to primary school. To this end, children's narratives were heard because it was believed that they can tell what happens to them and build meaning for their experiences. The objective of the research was: to analyze the senses attributed narratively by children regarding the transition from Early Childhood Education to Elementary School. Under the theoretical contribution of the (auto) biographical research in Education and Sociology of Childhood, the study was developed with six children from the first year of Elementary School. The results indicated that the transition between the two schools caused some tensions, since at the same time the children were attracted by the innovations offered by the new school, they felt fears, mourning and suffering, above all, with regard to the reduction of opportunities to play, the welcome and preparation of the school to receive them. For some children, the losses were compensated by the new learning, while others were suffering and did not have sufficient resources, needing more support to be included in this new stage. The adults responsible for teaching, hosting, and introducing the child to these institutions play a major role in adapting the child to this new stage. They are the ones who can be with the children, detect their needs and help them fit into this new context.
\end{abstract}

Keywords: (Auto)biographical research. Narratives. Nine-year elementary school. Transition.

\title{
Resumen
}

Este estudio tenía por objeto ampliar la comprensión de la transición de los niños de la educación de la primera infancia a la escuela primaria. Con este fin, las narraciones de los niños fueron escuchadas porque se creé que son capaces de contar lo que les pasa y construir un significado para sus experiencias. El objetivo de la investigación fue: analizar los sentidos atribuidos narrativamente por los niños en relación con la transición de la Educación Infantil a la Escuela Primaria. Bajo la contribución teórica de la investigación (auto)biográfica en Educación y Sociología de la Infancia, el estudio se desarrolló con seis niños del primer año de la Escuela Primaria. Los resultados indicaron que la transición entre las dos escuelas causó algunas tensiones, ya que al mismo tiempo que los niños se sentían atraídos por las innovaciones que ofrecía la nueva escuela, sentían temores, luto y sufrimiento, sobre todo en lo que respecta a la reducción de las oportunidades de juego, la acogida y la preparación de la escuela para recibirlos. Para algunos niños, las pérdidas fueron compensadas por el nuevo aprendizaje, mientras que otros estaban sufriendo y no tenían suficientes recursos, necesitando más apoyo para ser incluidos en esta nueva etapa. Los adultos responsables de la enseñanza, el cuidado 
y la introducción del niño en estas instituciones desempeñan un papel importante en la adaptación del niño a esta nueva etapa. Son ellos los que pueden estar con los niños, detectando sus necesidades, para ayudarles a encajar en este nuevo contexto.

Palabras clave: (Auto)investigación biográfica. Narrativas. Escuela primaria de nueve años. Transición.

As crianças, todas as crianças, transportam o peso da sociedade que os adultos Ihes legam, mas fazem-no com a leveza da renovação e o sentido de que tudo é de novo possível. (Sarmento, 2003)

\section{Introdução}

Leni-Bayle (2000) realizou uma pesquisa que coletou, no início do século XXI, narrativas de adultos sobre o tempo que passaram na escola. A pesquisa assumiu como ponto de partida a seguinte questão: o que resta do aluno no adulto que sou hoje? Esta pergunta, aparentemente simples, provocou um encontro entre o adulto e o aluno que ele foi e os resultados desse encontro colocaram à mostra as marcas profundas deixadas pela escola naqueles que a frequentam. Essa constatação impulsionou a formulação de outras perguntas e entre elas: o que restará da escola na memória das crianças que hoje a frequentam? O que elas podem contar a respeito de suas escolas hoje? Uma rede de pesquisa se formou e novas investigações surgiram lideradas por pesquisadores de diferentes países, entre eles o Brasil, em busca de compreender o que as crianças por meio de narrativas podem contar a respeito das escolas que frequentam (LENI-BAILE; PASSEGGI, 2014).

Neste texto, nos pautamos em uma das pesquisas que participou dessa rede e que se propôs ampliar a compreensão a respeito da percepção de crianças a respeito da passagem da Educação Infantil para o Ensino Fundamental. Uma questão norteou esse estudo: quais sentidos as crianças que concluíram a Educação Infantil atribuem à passagem dessa etapa para o Ensino Fundamental?

Escolhemos ouvir as narrativas das crianças por acreditar que, com base em pesquisas que realizamos anteriormente e nos referenciais que adotamos, as crianças que frequentam as escolas de infância são capazes de contar o que lhes acontece e de refletir e construir sentidos próprios para o que vivem em companhia de seus pares, 
num processo que Corsaro (2011) nomeia de reprodução interpretativa. As crianças não só se apropriam das culturas às quais pertencem, mas elaboram suas próprias culturas, ao formularem significações autônomas que diferem das produzidas pelos adultos. Ao ouvi-las compreendemos dimensões de suas vidas que muitas vezes nos passam despercebidas, seus modos de ver e interpretar o real, nos permitindo captar aspectos da cultura que não acessamos facilmente.

Este texto se organiza retomando a ideia de como a escola se estruturou desde a Modernidade, os modos como os marcos legais que formalizaram a entrada das crianças, aos seis anos de idade, no Ensino Fundamental. Oferece-se um espaço de reflexão sobre o potencial narrativo das crianças frente às experiências escolares e sobre o referencial teórico que sustentou tal perspectiva, seguido das análises realizadas sobre o material discursivo produzido por crianças egressas da Educação Infantil e que frequentam o primeiro ano do Ensino Fundamental.

\section{Como se estruturou a escola moderna?}

A escola, tal como se conhece na atualidade, começou a se estruturar na Idade Moderna, época em que passou a ter um papel civilizador nas sociedades ocidentais. Conforme explica Boto (2014), essas sociedades buscavam racionalizar gestos, comportamentos e, nesse cenário, a escola passou a cumprir um papel central na formatação das condutas e atitudes desde os primeiros anos da infância. "A história da moderna escolarização corresponde a um lento processo de organização de estilos e de rotinas que perfazem, a seu modo, um jeito específico e característico de transmissão de saberes, de valores e de maneiras de agir" (BOTO, 2014, p. 103).

Conforme explica Sarmento (2003), foi elaborado um conjunto de procedimentos que, pautado na construção de uma série de saberes sobre a criança, deu sustentação a uma administração simbólica da infância que culminou na estruturação ofício de aluno. Por ofício de aluno entendia-se o conjunto de traços comportamentais que, ligados à atividade escolar, passaram a ser considerados inerentes ao desempenho ativo das crianças, a partir da definição de papéis que, pouco a pouco, foram-lhes sendo imputados. 
A escola, portanto, passou a ser considerada a instituição social responsável pela construção e definição do que significava ser criança (BUCKINGHAM, 2002). Por meio da elaboração de intensos e marcantes traços culturais, produziu-se, desse modo, uma ideia de infância universal, definida a partir de idades e seriações, sem considerar suas capacidades e habilidades singulares. Conformou-se uma relação hierárquica entre o professor e aluno que impunha não apenas regras, mas também organizava os currículos, os horários, sem considerar as culturas infantis, suas opiniões, seus costumes e vivências.

Melhor dizendo, os tempos e espaços escolares, os conteúdos, símbolos e elementos que passaram a organizar o ambiente escolar, as rotinas e normas didatizadas passaram a constituir deliberada transmissão de uma cultura escolar. Adotou-se, desse modo, a ideia de espaço como objeto de representação de uma ordem social que operava indicando modos específicos de socialização por meio da organização do próprio espaço físico, das comunicações ali estabelecidas e das práticas realizadas (ANDRADE, 2013).

Conforme destaca Andrade (2015, p. 17), os espaços destinados às crianças passaram a ser organizados, conforme representações sobre o que é ser criança, a partir da perspectiva dos adultos e, por sua vez, definiram "modos infantis de ser e estar no mundo". A partir de reguladores sociais que definem o lugar da infância, assume-se uma postura epistemológica que não apenas justifica a organização dos espaços, mas orienta as práticas que se materializam no cotidiano.

No entanto, as crianças ao utilizarem esses espaços produziram novas significações que ultrapassaram aquelas construídas pelos adultos, incorporando novas formas de significação por meio de processos afetivos que envolvem não apenas a organização dos adultos sobre o currículo, dos horários e dos espaços, mas as relações que as próprias crianças estabelecem com a cultura, a memória social, as crenças, os valores, etc.

Desses encontros entre crianças, adultos e suas relações com o espaço surgem narrativas acerca da escola, ou, como explica Andrade (2015, p. 17), configura-se a noção de espaço narrativo, na medida em que o espaço passa a ter um sentido atribuído a partir das experiências empreendidas, constituindo, nessa medida, “a personificação de um lugar". De tal forma, analisar tais interações implica trabalho adicional no 
sentido de descortinar as bases que sustentam determinados modos de organização dos espaços e das práticas pedagógicas em detrimento de outras e oferecer uma compreensão sobre como o oficio de aluno é compreendido em tais configurações.

Considerando a complexidade que envolve o ingresso de crianças aos seis anos de idade no Ensino Fundamental, segundo Buckingham (2002) e Sarmento (2003), é perfeitamente possível situar um ofício de aluno que entra em choque com o ser criança, na medida em que a representação que se tem sobre ser aluno se desvela em práticas de um mundo escolarizado e direcionado a um futuro, cujo único objetivo é o de preparar o ser adulto.

Nessa perspectiva, desconsidera-se o presente, o mundo real e a cultura infantil, consolidando uma representação de criança como o ser da espera.

\section{O ingresso no Ensino Fundamental}

No Brasil, o ingresso das crianças aos seis anos de idade no Ensino Fundamental foi definido por meio da Lei no 11.114/05 (BRASIL, 2005a), que alterou os artigos 6, 32 e 87 da Lei n ${ }^{\circ} 9.394 / 1996$ (BRASIL, 1996). A isso se seguiu a ampliação do Ensino Fundamental para nove anos, por meio da Resolução CNE/CEB n n $^{\text {3, de }} 03$ de agosto de 2005 (BRASIL, 2005b), que deu nova redação aos artigos 32 e 87 da Lei n 9.394/1996 (BRASIL, 1996).

Em ambos os documentos, o que se verificou foi a prevalência de um debate que defendia a ideia de que quanto mais cedo a criança ingressasse no Ensino Fundamental, mais bem-sucedido seria seu processo de escolarização, sem que, no entanto, houvesse o necessário aprofundamento sobre as reflexões acerca das adaptações necessárias para que as crianças de seis anos de idade, até então abrangidas pela Educação Infantil, fossem recebidas no Ensino Fundamental.

Apenas em 2008, por meio do Parecer CNE/CEB nº 4 de 20 de fevereiro de 2008 (BRASIL, 2008), a atenção se voltou para as questões relacionadas à infância, tendo sido definidas orientações sobre o atendimento realizado nos três anos iniciais do Ensino Fundamental, com o ingresso compulsório das crianças aos seis anos de idade, a ser implementado até o ano de 2010, em todos os sistemas de ensino. 
Contudo, somente com a Resolução CNE/CEB n ${ }^{\circ} 7$ de 14 de dezembro de 2010 (BRASIL, 2010), que fixou Diretrizes Curriculares Nacionais para o Ensino Fundamental de 9 (nove) anos, foi atribuída atenção específica à articulação entre a Educação Infantil e o Ensino Fundamental, considerando a necessidade de valorização dos conhecimentos prévios dos estudantes e a recuperação do caráter lúdico no ensino, de modo a oferecer uma melhor qualificação das ações pedagógicas junto às crianças matriculadas nos anos iniciais do Ensino Fundamental.

Dentre os objetivos da Resolução CNE/CEB n 7, de 2010 (BRASIL, 2010), previstos em seu artigo 30, observam-se aqueles especificamente voltados aos três primeiros anos do Ensino Fundamental que, considerado como bloco pedagógico ou ciclo sequencial não sujeito a interrupções, visavam assegurar: a) a alfabetização e o letramento; b) o desenvolvimento das diversas formas de expressão; c) a continuidade das aprendizagens, mediante consideração do processo de alfabetização até o terceiro ano de escolaridade e a necessidade de garantir maior mobilidade das crianças dentro da sala de aula.

Dessa forma, o Ensino Fundamental de nove anos passou a ser considerado o meio pelo qual se tornaria possível "assegurar a todas as crianças um tempo mais longo de convívio escolar, maiores oportunidades de aprender e, com isso, uma aprendizagem mais ampla" (BRASIL, 2004, p. 17), corroborando a ideia de que tal ampliação possibilitaria maiores ganhos no que diz respeito à aprendizagem e à superação do fracasso escolar. Esses aspectos fizeram parte dos inúmeros documentos e manuais elaborados pelo Ministério da Educação, entre os anos de 2006 a 2009 (BRASIL, 2006; 2007; 2009; MACIEL; MONTEIRO, 2009), no sentido de assegurar aos profissionais da educação uma atuação mais ajustada às necessidades e peculiaridades das crianças que ingressavam no Ensino Fundamental, mas não foram amplamente integrados às propostas de formação inicial e continuada dos docentes.

Esse descompasso entre os manuais e a formação docente tornou-se um dos aspectos analisados entre pesquisadores e profissionais da área da Educação, uma vez que a ampliação do Ensino Fundamental não foi acompanhada pelos cursos de formação inicial e continuada dos professores que, segundo explica Kramer (2006), 
permaneceram sem subsídios mínimos para assegurar a adequada inserção de crianças mais novas no Ensino Fundamental.

O resultado que se observou, na prática, foi que a organização do currículo e a das práticas desenvolvidas nas salas de aula passaram a ser determinadas muito mais pela experiência que o professor possuía no Ensino Fundamental ou na Educação Infantil, portanto, a partir da relação de pertencimento com suas comunidades de origem, do que derivados dos documentos oficiais publicados (BONAMIGO, 2012).

Em outras palavras, o atendimento oferecido a crianças do primeiro ao terceiro ano se mostrava mais rígido e escolarizado na medida em que o professor acionava representações de alunos e de escola relacionadas ao Ensino Fundamental; o movimento inverso se observava em relação aos professores que tinham alguma experiência já consolidada na etapa da Educação Infantil. Tal aspecto se colocou como o grande desafio, na medida em que exigia, por parte dos profissionais da educação, uma apropriação dos novos manuais e, ao mesmo tempo, a negociação de sentidos atribuídos às diferentes etapas de ensino e que, até então, permaneciam apartadas.

O hibridismo decorrente de tais negociações implicou, segundo Furlanetto e Gomes (2016), a necessidade de se instalar, socialmente, uma discussão que permitisse analisar as finalidades da escola e as formas pelas quais tais finalidades se desenvolvem, considerando as questões legais, pedagógicas, formativas e estruturais e, sobretudo, os sentidos que as crianças atribuem a essa construção, contemplando suas especificidades, seus problemas e seus desafios.

\section{O potencial narrativo das crianças}

Para delinear teórica e metodologicamente a pesquisa, foi estabelecido um diálogo com autores que têm refletido sobre o potencial discursivo das crianças em narrar suas experiências e ao o fazerem, mostram-se capazes de atribuir sentidos ao vivido.

Segundo explica Corsaro (2011), as crianças contribuem ativamente para a preservação e também para a mudança social, na medida em que negociam, criam e 
compartilham cultura com os adultos e com seus pares, produzindo seus próprios saberes.

Entretanto, crianças vivem processos de significação que lhes são próprios, a partir das relações que estabelecem entre si e com os adultos. A apropriação que a criança faz da cultura do outro, seja da família ou de outros adultos, se dá por meio da apreensão do real e sua transformação mediante a atribuição de sentidos que lhes são próprios, não correspondendo ou se limitando aos processos de imitação ou de reprodução direta da cultura dos adultos, posto que de tal empreendimento surge um novo saber, uma nova cultura produzida e compartilhada por e entre crianças, oferecendo novas formas de interpretação da realidade na qual estão inseridas (SARMENTO, 2003; CORSARO, 2002; 2011).

Estudos desenvolvidos nos campos da Sociologia da Infância, da Pesquisa (auto)biográfica e da Psicologia Social têm contribuído para que pesquisadores se disponibilizem a ouvir as crianças e as considerem como capazes de expressar o que vivem, sentem e pensam, desconstruindo não apenas a ideia de uma criança universal, mas também evidenciando a existência de diferentes infâncias, considerando o tempo/espaço onde se desenrola a vida nessa etapa inicial.

Estudos como os de James e Prout (1997), Andrade (2015) e Qvortrup (2014) afirmam que as culturas infantis revelam uma variedade de infâncias, contrariando a ideia de criança como um ser único e universal e, por essa razão, faz-se necessário realizar pesquisas não mais sobre crianças, mas com crianças. Tal mudança de paradigma implica considerá-las como etapa geracional que compõe o tecido social mais amplo e, portanto, como atores sociais ativos que participam da construção de suas vidas e interferem nas vidas das pessoas com as quais convivem.

A mesma mudança de paradigma se insere em relação às atividades infantis, sobretudo, em relação ao brincar, pois, conforme explicam Kishimoto (2011a; 2011b) e Wajskop (1995), mais do que uma repetição da vida adulta, o brincar constitui uma experiência social, por meio da qual a criança encontra meios para representar, interpretar e comunicar suas experiências com o mundo, com a cultura e suas relações.

Nessa perspectiva de escuta da criança, Pinto e Sarmento (1997), Bruner (1997) e Demartini (2002) reforçam os argumentos que sustentam pesquisas com crianças e não sobre crianças, na medida em que as interpretações e sentidos que atribuem à 
realidade adquirem contornos totalmente distintos daqueles produzidos pelos adultos e se revelam por meio de seus próprios discursos e formas expressivas, desde a mais tenra idade.

Apostar nas narrativas infantis implica apostar na capacidade que as crianças possuem de apreender determinada realidade, atribuir-lhe novos sentidos incorporando os conhecimentos que possuem e construir um novo conhecimento que lhes permita interpretar a realidade na qual estão inseridas. Implica, portanto, reconhecer uma cultura própria, construída e compartilhada por e entre crianças, bem como seu potencial transformador; na medida em que narram suas experiências, nos permitem acessar o modo como percebem dada realidade.

Compreende-se, desse modo, o que Brockmeier e Harré (2003) definiram como uma virada discursiva e narrativa, na qual se insere pesquisa (auto)biográfica nas ciências humanas não apenas como método, mas como campo de investigação frente à crise do conhecimento moderno. Toma-se a pesquisa (auto)biográfica como posicionamento epistemológico que situa no centro das investigações a pessoa humana e sua capacidade de reflexão sobre si e sobre o mundo e os modos pelos quais se dão os processos de construção do sujeito na interação dialética entre o espaço social e o espaço pessoal (PINEAU, 2006).

Busca-se, desse modo, oferecer uma melhor compreensão sobre o modo como essas crianças dão forma às experiências, sentido à existência, na interação com o outro. Mais do que identificar regras universais e os fatos biográficos acontecidos em determinados momentos, as narrativas voltam-se para a análise dos sentidos que são atribuídos a tais fatos e das formas pelas quais esses acontecimentos são narrados. A narrativa constitui-se, dessa forma, como método de pesquisa e elemento a ser pesquisado (BRUNER, 1997; BROCKMEIER; HARRÉ, 2003; PINEAU, 2006; PASSEGGI, 2010).

Dessa forma, insere-se o presente estudo, tomando-se as narrativas infantis como ferramentas importantes para se compreender o sentido que as crianças de seis anos atribuem à escola, justamente numa fase de transição que comporta diferentes representações acerca do que é ser aluno, do papel da escola para essa faixa etária e da própria organização do currículo e das práticas pedagógicas. 


\section{Desenvolvimento}

O estudo pautou-se na abordagem qualitativa, mais especificamente na pesquisa (auto)biográfica, na qual as narrativas são tomadas como fontes capazes de explicitar as relações estabelecidas entre os sujeitos e o mundo no qual traçam suas vidas e, também, como ferramenta que possibilita uma reflexão sobre os modos pelos quais se constrói a experiência humana (PASSEGGI et al., 2014).

A investigação foi realizada com seis crianças que, após frequentarem a Educação Infantil, encontravam-se matriculadas no primeiro ano do Ensino Fundamental. Dentre os procedimentos exigidos pelo comitê de ética em pesquisa com seres humanos, cabe destacar a anuência dos responsáveis legais, mediante a assinatura de termo de consentimento livre e esclarecido e a anuência das próprias crianças. O número de crianças participantes foi considerado suficiente, levando-se em conta o desenho da pesquisa e a premissa de que "uma pessoa totaliza um sistema social", na medida em que as narrativas dessas crianças comportavam sistemas simbólicos e representações construídas coletivamente (PASSEGGI, 2010).

A coleta de dados contemplou duas etapas distintas, considerando a faixa etária e suas peculiaridades. A primeira foi desenvolvida por meio da realização de uma roda de conversa, escolhida por ser uma atividade já conhecida pelas crianças que frequentaram a Educação Infantil. A segunda voltou-se para a realização de uma entrevista, com o intuito de aprofundamento de alguns temas levantados durante a primeira etapa.

Na primeira etapa, foi utilizado um dispositivo de mediação (PASSEGGI et al., 2014) constituído por um boneco, que foi apresentado às crianças e, sendo novo naquele espaço, gostaria de saber o que as crianças pensavam sobre a escola. O local utilizado para essa etapa foi a sala de leitura e esse primeiro encontro teve a duração de cinquenta minutos. O procedimento de registro desse encontro foi a gravação em áudio e vídeo, seguido de transcrição na íntegra.

Na segunda etapa, cada criança foi chamada, individualmente, de modo que fosse possível esclarecer e aprofundar alguns dos temas levantados na etapa anterior. Esses momentos tiveram a duração aproximada de 10 a 20 minutos, e foram realizados sem o emprego das gravações, contando apenas com as anotações da entrevistadora. 
A leitura exaustiva dos dados permitiu o delineamento de categorias temáticas, que se transformaram em seis eixos de análise: 1. O brincar e o aprender; 2. Expressividade e movimento; 3. A organização do espaço da escola; 4. Alimentação no ambiente escolar; 5. O acolhimento dos pares e adultos; 6. As diferentes passagens.

\section{Apresentação e análise dos dados}

As crianças que participaram da pesquisa, como já foi salientado anteriormente, estão no primeiro ano do Ensino Fundamental e quando estimuladas a falar sobre a passagem da escola de Educação Infantil para a de Ensino Fundamental demostraram não apenas um conhecimento dos aspectos da cultura escolar, mas já exerciam o “ofício de aluno". Do mesmo modo, revelaram clareza sobre a função social da escola relacionada ao aprender e sinalizaram que a transição que estavam fazendo da Educação Infantil para Ensino Fundamental tinha o intuito de potencializar suas aprendizagens. Dentre as participantes, algumas pareceram atraídas pelas atividades oferecidas no Ensino Fundamental e, dessa forma, se mostraram disponíveis para viver novas experiências na escola.

Para Fernández (1991), as aprendizagens se ancoram numa estrutura lógica e cognitiva que privilegia a inteligência, mas também implica uma estrutura simbólica que envolve o desejo e o sentido. Enquanto o nível lógico se pauta na objetividade, o nível simbólico, por sua vez, permite subjetivar as aprendizagens. Os relatos das crianças explicitaram que elas queriam aprender a ler, a falar inglês, a usar o computador e estavam curiosas para conhecer novos professores. Ficou evidente que, entre essas crianças, havia uma atração pelo conhecimento escolar e a escola se configurava como um espaço onde isso poderia acontecer. No entanto, logo se revelaram, em suas narrativas, tensões existentes na escola. Aos poucos foram sinalizando que estavam perdendo algo, nesse momento de transição.

\section{O brincar e o apreender}

Considerando que os espaços onde a vida cotidiana se desenvolve constituem ao mesmo tempo "uma estrutura subordinada e subordinante, que se materializa em 
objetos, lugares e práticas sociais enraizadas nas relações e nos modelos culturais de uma época" (ANDRADE, 2013, p. 3), verificou-se que para algumas crianças a escola de Educação Infantil, que até então possibilitava espaços e tempos para o brincar articulado ao prazer, foi substituída, no Ensino Fundamental, por outro modelo que privilegiava os espaços e os tempos destinados exclusivamente para o desenvolvimento do ofício de aluno. Nesse novo modelo, o foco voltava-se, conforme relatado por parte das crianças, para os deveres de alunos e seus processos de aprendizagem, muitas vezes desconsiderando o caráter lúdico e prazeroso implicado no ato de aprender.

Conforme os relatos, para parte das crianças, o ato de aprender implicava abdicar do tempo do brincar e do prazer. Mais ainda, indicavam que brincar era coisa de criancinha e que, agora, a postura exigida seria a de preparação para o mundo adulto, para não correrem o risco, segundo suas palavras, de permanecerem burras.

As crianças têm que fazer toda a lição para ficar inteligente e aprender a ler. Mas aqui, a gente tem que aprender as coisas para não ficar burro, na EMEI que a gente brincava porque a gente era criança pequena. A professora que vai ensinar nós a fazer um monte de continha e escrever tudo.

As narrativas revelaram que essas crianças já se apropriaram de uma representação de escola na qual o aprender se opõe ao brincar e o dever, ao prazer. Diante disso, pode-se dizer que os elementos que estruturam a infância, como a ludicidade, o mundo do faz de conta e a relação espontânea entre os pares vão sendo, pouco a pouco, empurrados para as margens do Ensino Fundamental, para que as crianças possam caminhar em direção à maturidade: elas não têm mais direito de serem preguiçosas, barulhentas e brincalhonas.

Quem fez bagunça foi ele. A professora fala que ele é bagunceiro, porque ele fica correndo na sala.

Conforme explica Barbosa (2006), quando as crianças ingressam no Ensino Fundamental, há uma pressão social que exige que as crianças abram mão da infância, da conversa e da própria vida. Colocam-se em segundo plano as dimensões físicas, sociais, culturais, emocionais e cognitivas que o brincar oferece, desconsiderando seu papel mediador nas aprendizagens (KISHIMOTO, 2011a; 2011b). Retoma-se a representação de que o brincar se resume à imitação da vida adulta, desprovida de 
qualquer valor em si e, por essa razão, deveria ser substituído por outras atividades (KISHIMOTO, 2011a; 2011b; WAJSKOP, 1995; 2009).

Conforme observamos nas narrativas dessas crianças, algumas já percebiam que precisavam adequar seus comportamentos para serem aceitas, mesmo que isso implicasse sacrifício, uma vez que suas emoções e expressões, incluindo o choro, antes aceitas com mais tranquilidade, no Ensino Fundamental passaram a ser consideradas marcas de infantilidade e, por isso, menos aceitas. Neste contexto, novos códigos necessitam ser observados: além de brincar menos, também teriam que deixar de chorar ou pedir pela presença da mãe.

Lá, a outra escola é de criancinha, quando eu era pequena é que eu estudava lá. $\mathrm{Na}$ EMEI a gente brincava de um monte de "coisa". As "tia" era boazinha. Mas é que agora a gente vai "aprende" a ler. Algumas "lição" são legais, só as do livro que não.

Desse modo, verificou-se que nem todas as crianças pareciam preparadas para essa nova etapa, algumas se mostraram ressentidas e desejavam voltar para ambientes nos quais se sentiam mais seguras e acolhidas em suas manifestações.

\section{Expressividade e movimento}

As narrativas das crianças também revelaram o cerceamento que ocorria em relação ao corpo. Aprender, no Ensino Fundamental, requeria ficar mais tempo sentado, assumir as rotinas escolares e controlar as conversas com os amigos. Nesse novo contexto, segundo Charlot (2013), é exigida da criança uma maior disciplina que nem sempre cumpre uma função estruturante, uma vez que não se resume à organização do trabalho e à colaboração nas atividades, mas implica um controle corporal que inclui o silêncio e o domínio dos movimentos.

A respeito do controle do corpo e sua expressividade, cabe destacar que a aprendizagem enlaça a dimensão cognitiva e simbólica e, por essa razão, não é possível pensar um modelo de aprendizagem que não fique registrada no corpo. Se por um lado é necessária uma inibição do movimento para que haja pensamento, é necessário que o corpo não seja paralisado para que haja alegria e prazer (FERNÁNDEZ, 1991).

O que se pode perceber na fala das crianças é que, assim como o brincar, o corpo e sua potencialidade expressiva eram desconsiderados na sala de aula, no 
Ensino Fundamental. Suas narrativas indicavam que a estrutura, subordinada e subordinante, indicava o que delas era esperado: que ficassem atadas às suas carteiras, como condição imprescindível ao desempenho do ofício de aluno; ou, nas palavras de Férnandez (1991), amarrar o corpo para deixar apenas o cérebro em funcionamento.

Os resultados das narrativas confirmam o que Delory-Momberger (2014) e Furlanetto e Gomes (2016) sinalizaram: a escola, ao impedir a circulação difusa, conversas incontroladas e agrupamentos indecisos, faz com que a condução da classe passe pela condução do corpo.

As narrativas de algumas crianças sinalizavam inclusive o uso de punições e castigos como forma de controle. Desse modo, verificou-se que não havia mais a possibilidade de conversar com um colega, por exemplo.

Ele fica correndo na sala com o Felipe aí os dois ficam de castigo e chama a Dona Marisa para levar eles para conversar com a diretora e ela chama as mães aqui na escola. Eu não gosto, porque a professora põe de castigo e não deixa eu "fica" sentado perto do Murilo. E ele também mora no meu prédio.

\section{A organização do espaço escolar}

As crianças revelaram que, além de o corpo ser cerceado na sala de aula, havia um descaso, expressado por meio da estrutura física que não contemplava suas necessidades de brincar e de correr ou, nas palavras de Fernández (1991), de se expandirem.

A estrutura subordinada e subordinante do Ensino Fundamental se revelou com a indicação de um parquinho que não poderia ser utilizado por estar, segundo a narrativa de algumas crianças, todo quebrado - situação essa que não fazia parte da escola de Educação Infantil, conforme indica a sequência abaixo:

Pesquisadora: Você disse que gostava mais de estudar na sua outra escola? Por quê? Sim, lá tem tanque de areia.

Aqui não tem. Na minha também tinha tanque de areia e baldinho e pazinha para brincar. O parquinho daqui está todo quebrado. E cheio de sujeira.

Enquanto algumas crianças se adaptavam a esse espaço atribuindo novos sentidos a partir das expectativas que possuíam sobre suas aprendizagens, outras demonstravam uma menor identificação com o espaço, na medida em que não 
vislumbravam possibilidades de negociação com os adultos tampouco contavam com a legitimação de suas demandas por parte dos colegas.

Tais aspectos corroboram o estudo desenvolvido por Andrade (2013), na medida em que as formas de organização e negociação dos espaços podem trazer à tona elementos de bem-estar ou mal-estar ao indivíduo, levando-o a uma maior ou menor identificação com esse espaço.

Nesse sentido, analisar a postura de parte dos colegas frente àqueles que demandavam por mais espaços e brincadeiras nos permitiu compreender o quanto o coletivo condicionava a estruturação desse espaço (CORSARO, 2011) e acabava por influenciar a construção de suas identidades (pessoal e social), situando aqueles que reivindicavam os espaços para brincar no rol dos bagunceiros.

Na EMEI, eu adorava de mais o tanque de areia e o parque também. Todo dia nós ia no parque. Só quando chovia que não. (Levantando o dedo continua a fala) aqui a gente tem um monte de professora. Tem aula de informática com computador, a gente joga!

O que se observou, ao final das análises, foi que, apesar dos normativos e orientações elaborados pelo Ministério da Educação sobre o atendimento de crianças que ingressam no Ensino Fundamental, permanece uma distância entre o que se prescreve e aquilo que, de fato, se concretiza no espaço/tempo da escola.

Embora os documentos façam referência aos espaços educativos, aos materiais didáticos, ao mobiliário e aos equipamentos que precisam ser repensados para atender às crianças que ingressam no Ensino Fundamental (GONZÁLES ARROYO et al., 2007), há ainda um esforço que necessita ser empreendido para que o texto legal seja de fato colocado em prática. Segundo Costa (2009), são raros os espaços que contemplam parques infantis, brinquedotecas e materiais didáticos especificamente planejados para as crianças que ingressam no Ensino Fundamental.

\section{Alimentação no ambiente escolar}

A alimentação no ambiente escolar, segundo os documentos curriculares nacionais (BRASIL, 1997; 1998; 2006; 2017), se situa como temática que envolve, ao mesmo tempo, atos de cuidado e práticas educativas. Conforme explicam Pietruszynski et al. (2011), tais documentos preconizam propostas pedagógicas que 
favoreçam o desenvolvimento de práticas alimentares saudáveis, a formação de indivíduos conscientes e com hábitos de vida saudáveis, por meio de ações planejadas para esse fim que considerem seu caráter social e cultura.

Salientam ainda as autoras (PIETRUSZYNSKI et al, 2011) que trabalhar com a formação de novos hábitos alimentares exige ações especificamente planejadas para essa finalidade, envolvendo informações nutricionais, o incentivo a novas experimentações, sem que se perca de vista o seu caráter social e cultural.

Considerar a alimentação na escola como parte da prática educativa implica considerar a cultura alimentar das crianças, suas necessidades nutricionais e, também, considerar o papel ativo das crianças na construção de sua identidade alimentar, por meio das situações de troca que estabelecem entre os adultos e entre si, da possibilidade de fazerem suas próprias escolhas e de acessarem informações nutricionais dos alimentos que lhes são oferecidos (PIETRUSZYNSKI et al., 2011).

No entanto, para além do controle exercido sobre o corpo e suas manifestações expressivas, observou-se que mesmo durante os momentos de alimentação havia um cerceamento sobre as escolhas alimentares das crianças, na medida em que sinalizavam não poderem mais opinar sobre os alimentos que deveriam ser colocados em seus pratos, parecendo não haver qualquer trabalho pedagógico que favorecesse a ampliação dos hábitos alimentares das crianças e que considerasse a construção de suas identidades alimentares.

Eu gosto também da merenda daqui, só o leite que eu não gosto.

Não gosto não porque é ruim. A tia põe verdura. Eu não como na escola.

Eu não gosto de almoçar, eu almoço só na minha casa. Ah, porque eu gosto só de arroz e carne.

É que a tia põe tudo no prato.

Eu gostava da gelatina de uva. E não tem.

Na EMEI tinha bolinho com danone.

Conforme o relato de algumas crianças, o desejo e o prazer, bem como a dimensão educativa e socializadora da alimentação, foram substituídos pelo controle e pelo dever. Já não era mais possível recusar o feijão; a gelatina de uva e o bolinho com iogurte deixaram de fazer parte do cardápio. Por não se sentirem mais acolhidas e respeitadas, algumas crianças deixaram de se alimentar na escola, preferindo fazer suas refeições em casa. 


\section{O acolhimento dos pares e adultos}

Outra tensão verificada nas narrativas dos participantes dizia respeito ao seu relacionamento com as crianças mais velhas, sobretudo, nos horários de recreio. Observou-se que o horário do recreio dos alunos ingressantes no Ensino Fundamental não havia sido pensado de maneira adequada para acolhê-los, tampouco em relação às crianças mais velhas que os receberiam nesse espaço.

Embora permanecessem juntos nesses momentos de recreio, verificou-se o apontamento de sinais de desrespeito entre as crianças, dificultando essa entrada no Ensino Fundamental. As narrativas indicaram que essas crianças percebiam, ao mesmo tempo, um conflito com as crianças mais velhas e um distanciamento em relação aos adultos que pareciam desconhecer tais conflitos relacionais.

\footnotetext{
As tias só brigam quando as crianças fazem muita bagunça dentro do banheiro e joga comida para cima.

É porque no recreio dos "grandes" eles jogam água no chão do banheiro dos meninos e molha os pequenos e ficam entrando no banheiro das meninas. Pra puxar as outras meninas e as meninas ficam na porta e as vezes eu não consigo ir no banheiro.

Os meninos grande rouba os card's da gente. São do $4^{\circ}$ ano. Não, os "grande" são do $5^{\circ} \mathrm{A}$.
}

Dentre os relatos, ficou evidente que havia uma dificuldade relacional que estava sendo ignorada, na medida em que as crianças sinalizavam que os mais velhos jogavam água no banheiro e as impediam de utilizar esse espaço, ou quando tinham seus pertences confiscados pelos alunos do $5^{\circ}$ ano.

Nesses relatos, as crianças diziam que as professoras do Ensino Fundamental não eram tão acolhedoras como as das escolas anteriores; todavia, em contrapartida, reconheciam que essas professoras iriam lhes ensinar a ler, o que possibilitaria a introdução em um mundo novo, numa espécie de troca onde as relações deveriam ser substituídas pelos conteúdos escolares.

Nesse aspecto, verificou-se que a transição da Educação Infantil para o Ensino Fundamental modificava não apenas os objetivos e a forma de organização do espaço, mas atingia também as relações interpessoais, confirmando, desse modo, os resultados do estudo desenvolvido por Cintra e Almeida (2012).

A resposta das professoras, ante os conflitos relacionais, não se configurava como parte das estratégias de acolhimento pensadas para essa faixa etária, mas 
resumiam-se a ações pontuais de determinados adultos. Situação essa que nos remete ao estudo de Bonamigo (2012), que indicou haver estreita relação entre a atuação do professor do primeiro ano do Ensino Fundamental e sua experiência anterior nos segmentos da Educação Infantil ou do Ensino Fundamental.

\section{As diferentes passagens}

O tempo necessário para as crianças fazerem a passagem, da Educação Infantil para o Ensino Fundamental, pareceu ser diferente para cada uma. Barbosa (2007, p. 1065) mostra que não existe infância no singular, mas sim uma pluralidade de infâncias, marcadas por identidades sociais e pessoais que são permanentemente construídas. Compreende-se a infância não como noção unitária, mas como experiência social e pessoal, ativamente construída e continuamente ressignificada. As crianças não são e não existem como seres abstratos e generalizáveis, ao contrário, cada uma delas tem sua história de vida, que necessita ser considerada nesse momento de transição, tendo em vista que, dessa história, serão acionados os recursos que lhes garantirão maior ou menor adesão ao novo modelo.

Nesse sentido, algumas crianças mostraram que estavam se sentindo confortáveis no Ensino Fundamental, apesar das perdas que tiveram em relação, principalmente, ao brincar. Elas diziam estar interessadas em aprender e isso tornava a escola atraente.

Outras, no entanto, mostraram-se ainda reticentes em relação às mudanças e sinalizaram, claramente, o que perderam e o quanto essas perdas implicavam maior ou menor dificuldade de adesão à proposta do Ensino Fundamental.

No decorrer da conversa, demonstraram sentir falta da escola da Educação Infantil, em especial um dos alunos que, ao relutar em participar da roda de conversa, foi rapidamente tachado por seus colegas como sendo um garoto bagunceiro. A narrativa dessa criança colocou luz à sua dificuldade de não poder brincar, não poder correr e, do mesmo modo, revelou como suas atitudes desencadeavam uma série de condutas punitivas, ameaçadoras e até violentas por parte da professora que não apenas brigava, mas o expunha diante da classe chamando-o de criancinha e bagunceiro. 
Tal narrativa descortinou o desconforto dessa criança com a nova escola e evidenciou, também, que as ações desenvolvidas pelos educadores pareciam não facilitar a transição que deveria ser feita por ela. Do mesmo modo, verificou-se que seus colegas, incorporando as atitudes das professoras, o penalizavam por suas dificuldades, levando-o a uma recusa em participar da proposta, ante a rejeição que vivenciava junto ao seu grupo, e a declarar abertamente que não gostava da escola.

Suas maneiras e modos de se comportar passaram a ser considerados infantis e inadequados e sua dificuldade para incorporar os novos códigos passou a ser penalizada ao invés de acolhida. A forma como se comunicava, com os únicos recursos de que dispunha, era reconhecida, por seus professores e colegas, como indisciplina, imaturidade e, dessa forma, precisava ser punida.

Reforça-se a ideia de Cintra e Almeida (2012) de que o modo como o espaço é definido e organizado reflete-se em possibilidades que podem tanto estimular quanto limitar as aprendizagens. Mais do que isso, objetivam-se nos espaços as representações que os responsáveis por sua organização possuem sobre o que é ser criança e sobre o que é ser aluno e orientam-se práticas que confirmem tais representações (ANDRADE, 2015).

\section{Considerações finais}

O estudo teve por objetivo analisar os sentidos que crianças do primeiro ano do Ensino Fundamental atribuíam a essa nova etapa da escolarização. A partir das narrativas das crianças destacaram-se questões relacionadas à transição da Educação Infantil para o Ensino Fundamental que necessitam ser consideradas por aqueles que atuam nesse segmento educativo.

A transição da Educação Infantil para o Ensino Fundamental se apresentou como um momento de tensão para as crianças, na medida em que, ao mesmo tempo em que demonstravam se sentir atraídas pelas inovações apresentadas pela nova escola, revelavam temores, lutos e sofrimentos, sobretudo, no que se referia à recepção, ao acolhimento e à preparação da escola para recebê-los.

Em maior ou menor grau de dificuldade, sinalizaram que estavam se apropriando da nova cultura escolar e sendo capazes de se adaptarem às novas exigências, mesmo que isso exigisse um espaço-tempo menor para a ludicidade. 
Contudo, foi a partir da narrativa de uma criança que, apresentando maior dificuldade para fazer a transição da escola de Educação Infantil para a escola de Ensino Fundamental, se tornou possível analisar as tensões que necessitavam ser enfrentadas por todas.

O modo como cada criança indicava realizar essa passagem mostrou-se bastante peculiar e diretamente relacionado com suas experiências anteriores e com o grau de acolhimento que percebiam por parte dos adultos e no modo como esses adultos organizavam as propostas, os espaços e os tempos.

Explicitou-se que há um processo intenso e progressivo de aproximação e ressignificação da escola que necessita ser realizado por todas as crianças que ingressam no Ensino Fundamental, de modo que possam compreender e atender à nova cultura, suas rotinas e normas, desenvolvendo um novo ofício de aluno que, por vezes, entra em choque com suas histórias de vida e com a cultura infantil, na medida em que suas possibilidades expressivas nem sempre são consideradas e o brincar deixa de ser o meio pelo qual podem se apropriar dessa nova cultura escolar.

Cumpre destacar que os adultos responsáveis pelo acolhimento, inserção, desenvolvimento, ensino e socialização da criança nessas instituições têm um papel importante a desempenhar em relação ao desenvolvimento e adaptação da criança neste processo de transição. São eles que acompanham essa passagem e podem estar com as crianças, captando suas necessidades e suas singularidades, de forma a auxiliálas a se situarem nesse novo contexto, ou acrescentando práticas que podem dificultar o processo de adaptação.

Os resultados indicaram que os sentidos narrativos atribuídos por essas crianças ao Ensino Fundamental variavam entre a atração pelo saber e as novas possibilidades de aprendizagem, e as tensões no processo da aprendizagem do ofício de aluno. Do mesmo modo, sinalizaram que a escola pode se constituir tanto como espaço-tempo que favorece esses processos, na medida em que os adultos assumem compromisso constante no que diz respeito às relações que devem ser estabelecidas e ao acolhimento das manifestações infantis, quanto dificultar o processo de transição, quando não reconhecem as histórias de vida dessas crianças, suas múltiplas formas expressivas, seu corpo e suas necessidades como ponto de partida para o trabalho que necessita ser desenvolvido. 
Os achados desses estudos indicam que a inclusão de crianças de seis anos no primeiro ano do Ensino Fundamental requer diálogo institucional e pedagógico dentro da própria unidade e com a escola de Educação Infantil, de modo que seja possível tomar as vozes das crianças como ponto de partida para o planejamento dessa transição.

\section{Referências}

ANDRADE, D. B. S. F. Espaço como objeto e objetivação de representações sociais: elementos para pensar a formação de professores na educação infantil. In: CONGRESSO NACIONAL DE EDUCAÇÃO (EDUCERE), XI, 2013, Curitiba. Formaşão para mudanças no contexto da educação: políticas, representações sociais e práticas (Anais). Curitiba: PUCPR, 2013. p. $12.793-12.810$.

ANDRADE, D. B. S. F. O potencial narrativo dos lugares destinados às crianças: incursões do grupo de pesquisa em psicologia da infância GPPIN. Fractal: Revista de Psicologia, Rio de Janeiro, v. 27, n. 1, p. 16-21, abr. 2015.

BARBOSA, M. C. S. O ensino obrigatório aos 6 anos e sua ampliação para 9 anos trará vantagens ou não aos alunos? Revista Pátio Pedagógica, São Paulo, v. 10, n. 37, p. 50-53, fev./abr. 2006.

BARBOSA, M. C. Culturas escolares, culturas de infância e culturas familiares: as socializações e a escolarização no entretecer destas culturas. Educação e Sociedade, Campinas, v. 28, n. 100, p. 1059-1083, out. 2007. Edição especial.

BONAMIGO, C. C. A criança de seis anos no ensino fundamental: hibridismo de um currículo entre o instituído e o não instituído. In: COLÓQUIO SOBRE QUESTÕES CURRICULARES E COLÓQUIO LUSO BRASILEIRO DE CURRÍCULO, X; VI, 2012, Belo Horizonte. Desafios contemporâneos no campo do currículo (Anais), Belo Horizonte: UFMG, 2012. p. 1-15.

BOTO, C. A liturgia da escola moderna: saberes, valores, atitudes e exemplos. Revista História da Educação, Santa Maria, v. 18, n. 44, p. 99-127, dec. 2014.

BRASIL. Lei $\mathrm{n}^{\circ}$ 9.394, 20 de dezembro de 1996. Estabelece as diretrizes e bases para a educação nacional. Diário Oficial da União. Brasília, DF, 23 dez. 1996. Disponível em: http://www.mec.gov.br. Acesso em: 10 jun. 2015.

BRASIL. Secretaria de Educação Fundamental. Parâmetros curriculares nacionais. Brasília: MEC/SEF, 1997.

BRASIL. Ministério da Educação e do Desporto, Secretaria de Educação Fundamental. Referencial curricular nacional para a educação infantil. Brasília: MEC/SEF, 1998.

BRASIL. Ministério da Educação. Secretaria de Educação Básica, Departamento de Políticas de Educação Infantil e Ensino Fundamental, Coordenação-Geral do Ensino Fundamental. Ensino fundamental de nove anos: orientações para a inclusão da criança de seis anos de idade. Brasília: SEB, DPE, COEF, 2004. Disponível em: 
http://portal.mec.gov.br/seb/arquivos/pdf/Ensfund/noveanorienger.pdf. Acesso em: 16 set. 2019.

BRASIL. Lei no 11.114, de 16 de maio de 2005. Altera os arts. $6^{\circ}, 30,32$ e 87 da Lei no 9.394, de 20 de dezembro de 1996, com o objetivo de tornar obrigatório o início do ensino fundamental aos seis anos de idade. Diário Oficial da União. Brasília, DF, 20 dez. 2005a. Disponível em: http://www.planalto.gov.br/ccivil_03/_ato2004-2006/2005/lei/111114.htm. Acesso em: 13 maio 2020.

BRASIL. Ministério da Educação. Conselho Nacional de Educação. Resolução CNE/CEB $n^{\circ} 3 / 2005$. Define normas nacionais para a ampliação do Ensino Fundamental para 9 (nove) anos de duração. Diário Oficial da União. Brasília, DF, 08 ago. 2005b. Disponível em: http://portal.mec.gov.br/cne/arquivos/pdf/rceb003_05.pdf. Acesso em: 16 set. 2019.

BRASIL. Ministério da Educação. Secretaria de Educação Básica. Parâmetros nacionais de qualidade para a educação infantil. Brasilia, DF: Ministério da Educação, Secretaria de Educação Básica, 2006. Disponível em: http://portal.mec.gov.br/seb/arquivos/pdf/Educinf/eduinfparqualvol1.pdf. Acesso em: 13 maio 2020.

BRASIL. Ministério da Educação. Secretaria de Educação Básica. Ensino Fundamental de nove anos: orientações para a inclusão da criança de seis anos de idade. Brasilia: Departamento de Políticas de Educação Infantil e Ensino Fundamental; Coordenação-Geral do Ensino Fundamental, 2007. Disponível em: http://portal.mec.gov.br/seb/arquivos/pdf/Ensfund/ensifund9anobasefinal.pdf. Acesso em: 20 jan. 2020.

BRASIL. Ministério da Educação. Conselho Nacional de Educação. Parecer CNE/CEB n ${ }^{\circ}$ 4/2008. Orientação sobre os três anos iniciais do Ensino Fundamental de nove anos. Diário Oficial da União. Brasília, DF, 08 ago. 2008. Disponível em: http://portal.mec.gov.br/cne/arquivos/pdf/2008/pceb004_08.pdf. Acesso em: 16 set. 2019.

BRASIL. Ministério da Educação; Secretaria de Educação Básica. Ensino Fundamental de nove anos: passo a passo do processo de implantação. Brasilia, DF: Departamento de Políticas de Educação Infantil e Ensino Fundamental; Coordenação-Geral do Ensino Fundamental, 2009. Disponível em: http://portal.mec.gov.br/dmdocuments/passo_a_passo_versao_atual_16_setembro.pdf. Acesso em: 13 maio 2020.

BRASIL. Ministério da Educação. Conselho Nacional de Educação. Resolução CNE/CEB $\mathrm{n}^{\mathrm{o}} 7 / 2010$. Fixa Diretrizes Curriculares Nacionais para o Ensino Fundamental de 9 (nove) anos. Diário Oficial da União. Brasília, DF: 15 dez. 2010. Disponível em: http://portal.mec.gov.br/dmdocuments/rceb007_10.pdf. Acesso em: 16 set. 2019.

BRASIL. Ministério da Educação. Conselho Nacional de Educação. Conselho Pleno. Resolução n ${ }^{\circ}$ 2/2017. Institui e orienta a implantação da Base Nacional Comum Curricular, a ser respeitada obrigatoriamente ao longo das etapas e respectivas modalidades no âmbito da Educação Básica. Diário Oficial da União. Brasília, DF, 22 dez. 2017.

BROCKMEIER, J.; HARRÉ, R. Narrativa: problemas e promessas de um paradigma alternativo. Psicologia: Reflexão e Crítica, Porto Alegre, v. 16, n. 3, p. 525-535, 2003.

BRUNER, J. S. Atos de significação. Porto Alegre: Artes Médicas, 1997.

BUCKINGHAM, D. Crecer en la era de los medios electrónicos: tras la muerte de la infancia. Madrid: Morata; Fundación Paideia, 2002. 
CHARLOT, B. A mistificação pedagógica: realidades sociais e processos ideológicos na teoria da educação. São Paulo: Cortez, 2013.

CINTRA, F. B. M.; ALMEIDA, L. R. A criança de seis anos no ensino fundamental: a questão do movimento. In: COLÓQUIO SOBRE QUESTÕES CURRICULARES E COLÓQUIO LUSO BRASILEIRO DE CURRÍCULO, X; VI, 2012, Belo Horizonte. Desafios contemporâneos no campo do currículo (Anais), Belo Horizonte: UFMG, 2012. p. 1-15.

CORSARO, W. A reprodução interpretativa no brincar ao "faz-de-conta" das crianças. Educação, Sociedade e Cultura: Revista da Associação de Sociologia e Antropologia da Educação, Porto, v. 17, p. 113-134, 2002.

CORSARO, W. Sociologia da Infância. Porto Alegre: Artmed, 2011.

COSTA, S. S. Ensino Fundamental de nove anos em Goiânia: o lugar da criança de seis anos, concepções e fundamentos sobre sua educação. 2009. 251 f. Tese (Doutorado) - Faculdade de Educação, Universidade Federal de Goiás, Goiânia, 2009.

DELORY-MOMBERGER, C. (org.). Éprowver le corps: corps appris, corps apprenant. Toulouse: Érès, 2014.

DEMARTINI, Z. Infância, pesquisa e relatos orais. In: FARIA, A. L.; DEMARTINI, Z. B. F.; PRADO, P. D. (org.). Por uma cultura da infância: metodologia de pesquisa com crianças. Campinas: Autores Associados, 2002. p. 1-17.

FERNÁNDEZ, A. A inteligência aprisionada: abordagem psicopedagógica clínica da criança e sua família. Porto Alegre: Artes Médicas, 1991.

FURLANETTO, E. C.; GOMES, M. O. Narrativas de crianças, infâncias e formação de professores: possíveis relações. In: REIS, M.; BORGES, R. R. (org.). Educação infantil, arte, cultura e sociedade. Curitiba: CRV, 2016, p. 67-78.

GONZÁLES ARROYO, M. et al. Indagações Sobre Currículo: educandos e educadores, seus direitos e o currículo. Brasília: Ministério da Educação, Secretaria da Educação Básica, 2007. Disponível em: http://portal.mec.gov.br/seb/arquivos/pdf/Ensfund/indag2.pdf. Acesso em: 20 jun. 2015.

JAMES, A.; PROUT, A. A new paradigm for the sociology of childhood? Provenance, promise and problems. In: JAMES, A.; PROUT, A. (org.). Constructing and reconstructing childhood: contemporary issues in the sociological study of childhood. London: Falmer Press, 1997. p. 7-34.

KISHIMOTO, T. M. O brincar e suas teorias. São Paulo: Cengage, 2011a.

KISHIMOTO, T. M. O jogo e a educação infantil. In: KISHIMOTO, T. M .(Org). Jogo, brinquedo, brincadeira e a educação. São Paulo: Cortez, 2011b.

KRAMER, S. As crianças de 0 a 6 anos nas políticas educacionais no Brasil: educação infantil e/é fundamental? Educação e Sociedade, Campinas, v. 27, n. 96, p. 797-818, out. 2006.

LENI-BAYLE, M. (org.). Raconter l'école au cours du siècle. Paris: L'Harmattan, 2000.

LENI-BAYLE, M.; PASSEGGI, M. C. (org.). Raconter l'école: à l'écoute de vécus scolaires en Europe et au Brésil. Paris: L'Harmattan, 2014. 
MACIEL, F. I. P.; MONTEIRO, S. M. (org.). A criança de 6 anos, a linguagem escrita e o ensino fundamental de nove anos: orientações para o trabalho com a linguagem escrita em turmas de crianças de seis anos de idade. Belo Horizonte: UFMG/FaE/CEALE, 2009. Disponível em: http://portal.mec.gov.br/index.php?option $=$ com_docman\&view $=$ download\&alias $=4034$-criancaseis-anos-opt\&category_slug=marco-2010-pdf\&Itemid=30192. Acesso em: 10 abr. 2020.

MEDEIROS, A. S. Narrativas de crianças de seis anos que estão entrando no primeiro ano do ensino fundamental. 2016. Dissertação (Mestrado em Educação) - Faculdade de Educação, Universidade Cidade de São Paulo, São Paulo, 2016.

PASSEGGI, M. C. Narrar é humano! Autobiografar é um ato civilizatório. In: PASSEGGI, M. C.; SILVA, V. B. (org.). Invenções de vida, compreensão de itinerários e alternativas de formação. São Paulo: Cultura Acadêmica, 2010. p. 103-130.

PASSEGGI, M. C. F. B. S. et al. Narrativas de crianças sobre as escolas da infância: cenários e desafios da pesquisa (auto)biográfica. Educação, Santa Maria, v. 39, p. 85-104, 2014.

PIETRUSZYNSKI, E. B. et al. (2011). Práticas pedagógicas envolvendo a alimentação no ambiente escolar: apresentação de uma proposta. Revista Teoria e Prática da Educação, Rio Claro, v. 13, n. 2, p. 223-229, maio./ago. 2010.

PINEAU, G. As histórias de vida em formação: gênese de uma corrente de pesquisa-açãoformação existencial. Educação e Pesquisa, São Paulo, v.32, n.2, p. 329-343, maio/ago. 2006.

PINTO, M.; SARMENTO, M. J. (org.). As crianças: contextos e identidades. Braga: Ed. Centro de Estudos da Criança, Universidade do Minho, 1997.

QVORTRUP, J. Visibilidade das crianças e da infância. Linhas Críticas, Brasília, DF, v. 20, n. 41, p. 23-42, jan./abr. 2014.

SARMENTO, M. J. Imaginário e culturas infantis. Cadernos de Educação, Pelotas, n. 21, p. 51-59, jul./dez. 2003.

WAJSKOP, G. Brincar na pré-escola. 8 ed. São Paulo: Cortez, 2009.

WAJSKOP, G. O brincar na educação infantil. Cadernos de Pesquisa. São Paulo, n. 92, p. 62-69, fev. 1995. Disponível em: http://publicacoes.fcc.org.br/ojs/index.php/cp/article/view/859. Acesso em: 24 mar. 2020.

RECEBIDO: $30 / 05 / 2020$

APROVADO: $28 / 07 / 2020$

RECEIVED: 05/30/2020

APPROVED: 07/28/2020

RECIBIDO: $30 / 05 / 2020$

APROBADO: 28/07/2020 